Full-text Available Online at www.bioline.org.br/ja
J. Appl. Sci. Environ. Mgt. September, 2006

Vol. 10 (3) 15 - 20

\title{
Tendu leaves refuse as a Biosorbent for COD removal from Molasses Fermentation based Bulk Drug Industry Effluent.
}

\author{
*NAGDA, G K; GHOLE, V S; DIWAN, A M \\ Department of Environmental Sciences, University of Pune, Pune, India.
}

\begin{abstract}
Physico-chemical properties of effluent from a molasses fermentation based bulk drug unit were analyzed and found to be typical of the effluent from molasses fermentation except for high amount of phenols. The Chemical Oxygen Demand (COD) removal capacity of tendu (Diospyros melanoxylon) leaves refuse of bidi industry and its comparison with Granulated Activated Carbon (GAC) has been presented. Batch kinetics and isotherm studies were studied under varying experimental conditions of contact time, COD concentration, adsorbent dose and $\mathrm{pH}$. Maximum COD removal was observed at a narrow $\mathrm{pH}$ range between 7 and 8 . The kinetic data were best fitted to the pseudo-second-order chemisorption model. The adsorption followed both Langmuir and Freundlich isotherms. As per Langmuir model, maximum adsorption capacity was found to be $48.54 \mathrm{mg}$ and $154.8 \mathrm{mg}$ COD per $\mathrm{g}$ for tendu leaves refuse and GAC, respectively. The results illustrate how tendu leaves refuse, a solid waste disposal menace from bidi industry, is effective biosorbent for the removal of COD; offering a cheap option for primary treatment of the effluent. @JASEM
\end{abstract}

Fermentation technology is a fast growing area of biotechnology and important metabolites such as enzymes, antibiotics, drugs, organic acids and many other bio-molecules are generally obtained from fermentative activity. The fermentation industry may be broadly categorized as molasses-based and nonmolasses-based considering the main substrate used in the fermentation process. The Molasses based fermentation industry has been identified to be one of the most polluting industries due to the very high organic pollutant load associated with its waste discharges (Lewicki, 2001). In terms of environmental impacts, fermentation industry, do show some differences in the effluent characteristics, brought about by the fermentation practices and byproduct recovery processes used. Treatment technologies needed to reduce the pollutant load of fermentation effluent to a level considered safe for disposal back to the water bodies have been found to involve exorbitantly high costs. Several methods for the treatment, utilization and disposal of effluent from fermentation industries are used. Among these are both chemical and biological treatments such as aerobic or anaerobic classical methods, trickling filters, lagoons, and evaporation-condensation with or without combustion, direct dispersion on soil as a fertilizer, etc. (Maiorella et al., 1983). The aerobic treatment of high-organic load wastes is associated with operational difficulties of sludge bulking and inability of the system to treat high COD loads economically (Hickey and Goodwin, 1989). Recently organic pollutants from bulk drug industry were treated by electrochemical treatment (Rajkumar and Palanivelu, 2004) and anaerobic treatment using fixed film reactor (Gangani Rao et. al., 2004). For bio-refractory COD removal ozonation has been used as an end treatment (Baig and Liechti, 2001).

Adsorption as a primary treatment process offers effective and economical alternative, however adsorption of organic matter is slow and seldom reaches equilibrium (Sontheimer et al., 1988). The adsorbent that is used in practice remains activated carbon. However because of high cost of activated carbon, its use is sometimes restricted on economical considerations. Natural biodegradable waste materials from industrial and agricultural operations may have potential as inexpensive adsorbents. A range of products has been examined. These include Coir Pith (Namasivayam et al., 2001), Bagasse Pith (Krishnan and Anirudhan, 2002), Cassava Waste (Abia et al., 2003), Soya Cake (Gupta et al., 2005) and Eucalyptus bark (Sarin and Pant, 2006) just to mention a few.

Tendu (Diospyros melanoxylon) leaves refuse is generated during the manufacture of Indian crude cigarette, also called Bidi. Bidi is an indigenous crude cigarette in which tobacco is hand-rolled in a small cut portion of tendu leaf and tied with a cotton thread. Tendu leaf is used as Bidi wrapper on account of the ease with which it can be rolled and its wide availability. It also has agreeable flavor, resistance to decay and capacity to retain fires. Bidi rolling is a major home industry covering thousands of homes, particularly in the industrial towns of Jabalpur and Solapur in India. This home industry of bidi making, produces cuttings of tendu leaves as refuse which 
pollutes the dumping sites creating solid waste disposal problem of alarming scale. About 7200 tonnes of tendu leaves waste is generated per annum in the industrial town of Solapur, India (Kadam, 2004). In the present work the potential of tendu leaves refuse as a biosorbent has been examined. The COD removal from molasses fermentation based bulk drug industry effluent as related to various adsorption process parameters was studied.

\section{MATERIALS AND METHODS}

The untreated effluent was obtained from Biotechnology division of M/s. Avon organics Ltd, Solapur, manufacturing ephedrine hydrochloride using molasses based fermentation method. Various effluent parameters were determined by APHA methods (APHA, 1989). Organic carbon, total nitrogen, phosphorus and potash were determined using standard methods (Chapman and Pratt, 1961). Physico-chemical characteristics of the effluent are listed in Table 1.

The tendu leaves refuse were obtained from the dumping sites near bidi industries in the town of Solapur, India. They were cut in to small pieces of about $2 \mathrm{~mm}$ and were thoroughly washed with distilled water to remove all dirt and were dried at $80^{\circ} \mathrm{C}$ till constant weight. The dried tendu leaves refuse (TLR) were powdered and sieved with an 80mesh sieve and stored in dessicator until used. Activated carbon and other chemicals used were of analytical grade.

Adsorption studies were performed in batch method, using 250ml effluent of desired COD concentration in 500ml Erlenmeyer flasks and know amount of
TLR and GAC were added to each flask. The flasks were maintained at $30^{\circ} \mathrm{C}$ under constant stirring on a magnetic stirrer at $100 \mathrm{rpm}$. Samples were removed at different time intervals, centrifuged and analyzed for COD. The uptake was calculated from the difference between the initial and final COD concentration. All experiments were carried out in triplicate with respect to each condition and mean values were used for further calculations. The maximum deviation was $2.5 \%$.

\section{RESULTS AND DISCUSSION:}

The COD removal from the effluent by tendu leaves refuse (TLR) was evaluated and compared with Granulated Activated Carbon (GAC) by optimizing various physicochemical parameters such as $\mathrm{pH}$, contact time, and the amount of adsorbent and adsorbate.

Effect of $\mathrm{pH}$ on phenol removal: In any adsorbateadsorbent system, $\mathrm{pH}$ of the system affects the nature of surface charge of the adsorbent, ionization and the extent and rate of adsorption. Several $500 \mathrm{ml}$ portions of 210mg COD/L of effluent solution were adjusted to assigned $\mathrm{pH}$ with sodium hydroxide or sulfuric acid. Equal quantity of TLR and GAC were added to the flasks containing various assigned $\mathrm{pH}$ and stirred for $2 \mathrm{hr}$. Measurement of initial and final COD concentration gave the percent removal of COD. The removal of COD by TLR and GAC at various $\mathrm{pH}$ values is displayed in Fig.1. Adsorbed amount was fairly constant over a wide range of $\mathrm{pH}$ in case of GAC, while TLR has efficient removal at a narrow range between $\mathrm{pH} 7$ and $\mathrm{pH} 8$.

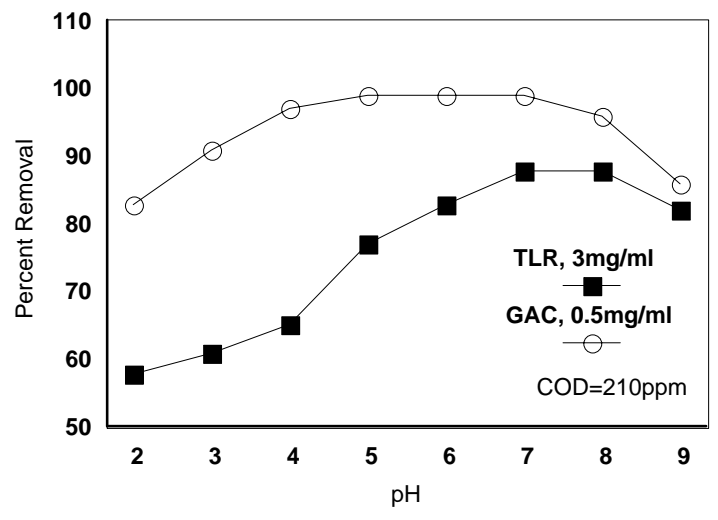

Fig 1. Effect of $\mathrm{pH}$ on COD removal 
Table 1: Physico-chemical properties of Molasses based Bulk Drug Fermentation Industry Effluent. $(n=10)$

\begin{tabular}{llll}
\hline Parameters & Mean & Range & \pm S.D \\
\hline Color & Dark Brown & - & - \\
PH & 3.84 & $3.57-4.12$ & 0.18 \\
Electrical Conductivity, $\mu \mathrm{S} / \mathrm{cm}^{2}$ & 12.41 & $11.1-15.68$ & 1.25 \\
Suspended solids, mg/l & 5320 & $4400-6200$ & 635.04 \\
Dissolved solids, mg/l & 64140 & $58600-72100$ & 4663.3 \\
B.O.D., mg/l & 62460 & $53200-69100$ & 4141.3 \\
C.O.D., mg/l & 111420 & $97600-128000$ & 8762.3 \\
Phenols, mg/l & 471.5 & $410-550$ & 37.62 \\
Organic Matter, \% & 5.49 & $4.62-6.48$ & 0.59 \\
Total Nitrogen, \% & 4.88 & $4.11-5.7$ & 0.46 \\
Phosphorus, \% & 0.42 & $0.36-0.52$ & 0.05 \\
Potash, \% & 0.83 & $0.64-0.95$ & 0.09 \\
\hline
\end{tabular}

Effect of adsorbent concentration: The effect of adsorbent concentration on COD removal was studied where various amounts of TLR and GAC were added to a fixed initial COD concentration. Adsorbent dosage was varied from $1 \mathrm{~g}$ to $10 \mathrm{~g}$ and $0.2 \mathrm{~g}$ to $5 \mathrm{~g}$ for TLR and GAC, respectively. The residual COD was measured in the solution at equilibrium and results are shown in Fig. 2. The percent COD removal increases with increase in adsorbent concentration as the number of adsorbent particles increases. At neutral $\mathrm{pH}, 88 \%$ COD removal from initial concentration of $265 \mathrm{mg} / \mathrm{l}$ COD was achieved within 6 hrs of contact time with TLR.

Table2 Adsorption isotherm parameters for the adsorption of COD

\begin{tabular}{l|llllll} 
Adsorbent & Langmuir & \multicolumn{5}{c}{ Freundlich } \\
\hline \multirow{3}{*}{ TLR } & $\mathrm{K}_{\mathrm{L}},(\mathrm{mg} / \mathrm{g})$ & $\mathrm{b},(\mathrm{mg} / \mathrm{g})$ & $\mathrm{R}^{2}$ & $\mathrm{~K}_{\mathrm{F}}$ & $N$ & $\mathrm{R}^{2}$ \\
GAC & 0.023 & 48.54 & 0.984 & 3.664 & 2.045 & 0.996 \\
& 0.075 & 154.8 & 0.932 & 42.66 & 3.861 & 0.959
\end{tabular}
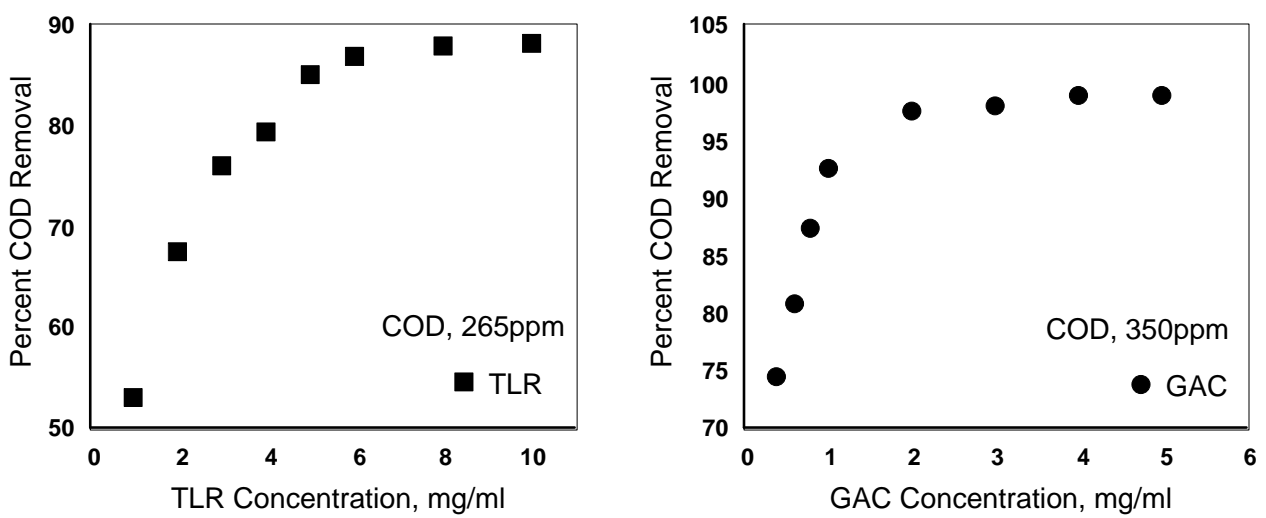

Fig 2. Effect of adsorbent concentration on COD removal by TLR and GAC

Adsorption Kinetics: COD removal by TLR and GAC at different contact time were studied in batch experiments and shown in Fig, 3 at different initial COD concentration ranging from 90 to $400 \mathrm{ppm}$. The adsorbent mass used was $5 \mathrm{mg} / \mathrm{ml}$ for TLR and $2 \mathrm{mg} / \mathrm{ml}$ for $\mathrm{GAC}$ at $30^{\circ} \mathrm{C}$ and at $\mathrm{pH}$ value of 7.2 . The results also show that equilibrium time required for the adsorption of COD on TLR and GAC are 6hr and $2 \mathrm{hr}$ respectively. The adsorption of COD onto the biosorbent suggests that intra-particle diffusion is the limiting factor in this latter portion of the process. The kinetic data fits best in the Ho's pseudo-second- 
order chemisorption model (Ho and McKay, 1999) as shown in Fig. 3. The pseudo-second order equation is based on the sorption capacity on the solid phase. It predicts the behavior over the whole range of studies supporting a pseudo-second order equation and is in agreement with chemisorption being the rate-limiting step. The pseudo-second-order rate expression of Ho (Ho and McKay, 1999) has been applied widely to the sorption of metal ions, dyes, oils and organic substances from aqueous systems.
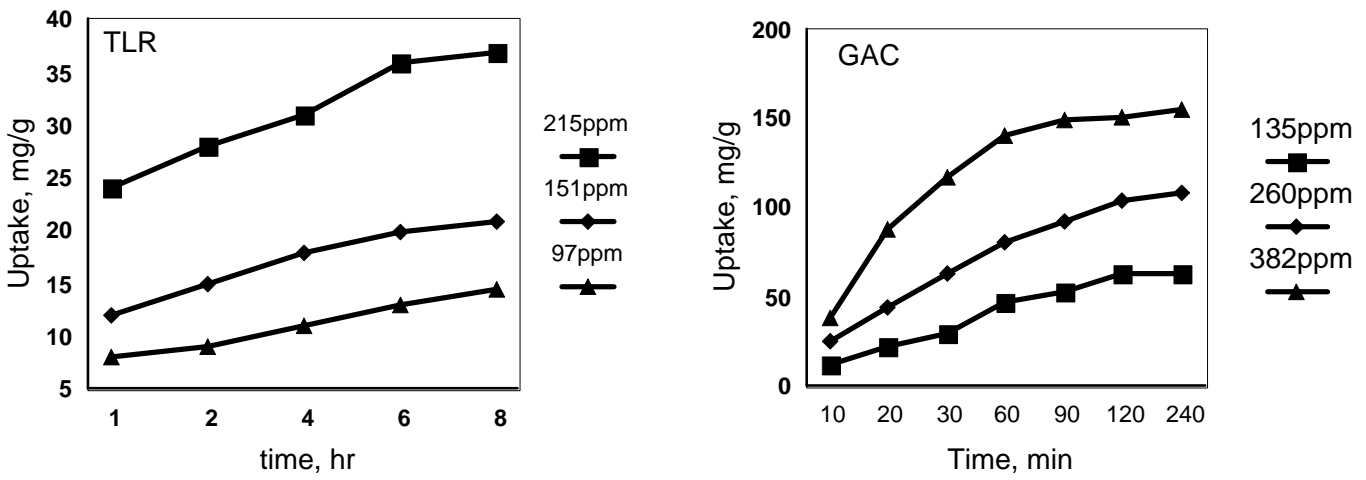

Fig 3. Kinetics of COD removal at various concentrations TLR and GAC

Adsorption Isotherms: It essentially expresses the relation between the concentrations of the solute in solution at dynamic equilibrium with the concentration of the solute adsorbed onto the adsorbent at constant temperature. Several models have been published in the literature to describe experimental data of which the most common are the Langmuir isotherm and the Freundlich isotherm (Casey, 1997). The linearized Langmuir model, typical for monolayer adsorption, can be written as

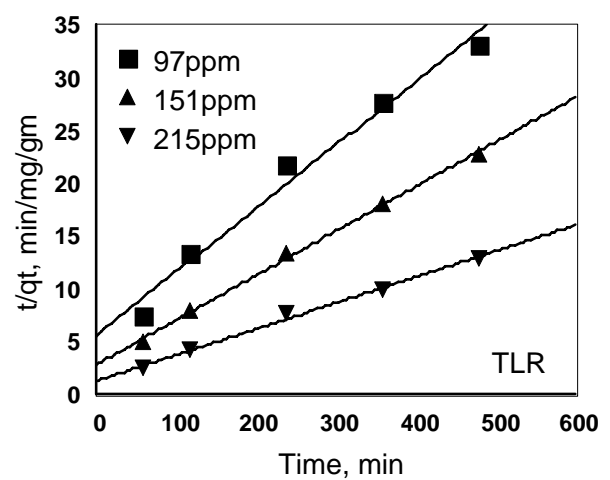

$1 / \mathrm{Q}_{\mathrm{e}}=1 / \mathrm{K}_{\mathrm{L}}+1 / \mathrm{bK}_{\mathrm{L}} * 1 / \mathrm{C}_{\mathrm{e}}$

Where $\mathrm{C}_{\mathrm{e}}$ is the concentration of COD at equilibrium (mg/l), $Q_{e}$ is the amount of COD adsorbed at equilibrium (mg/g), $\mathrm{K}_{\mathrm{L}}(\mathrm{mg} / \mathrm{l})$ and $\mathrm{b}(\mathrm{mg} / \mathrm{g})$ are the Langmuir constants, representing the maximum adsorption capacity for the solid phase loading and the energy constant related to the heat of adsorption. The constants $\mathrm{b}$ and $\mathrm{K}_{\mathrm{L}}$ can be evaluated from the intercept and slope of the linear plot of the experimental data of $1 / \mathrm{Q}_{\mathrm{e}}$ versus $1 / \mathrm{C}_{\mathrm{e}}$, respectively.

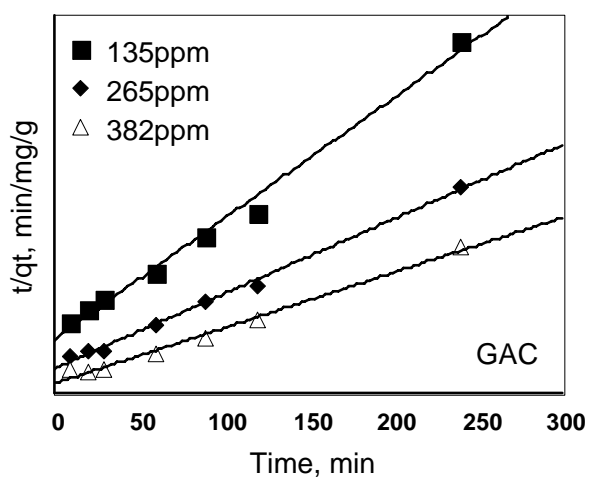

Fig 4. Pseudo-second-order kinetics of COD uptake by TLR and GAC

The Freundlich isotherm has been widely adopted to characterize the adsorption capacity of organic pollutants using different adsorbents by fitting the adsorption data.

The Freundlich isotherm in its linearized form can be written as:

$\log \mathrm{Q}_{\mathrm{e}}=\log \mathrm{K}_{\mathrm{F}}-1 / n * \log \mathrm{C}_{\mathrm{e}}$
Where, $K_{F}$ is a Freundlich constant related to the adsorption capacity, and $1 / \mathrm{n}$ is the intensity of adsorption. The values of $\mathrm{K}_{\mathrm{F}}$ and $1 / n$ can be determined from the intercept and slope, respectively of linear plot of $\log Q_{e}$ versus $\log C_{e}$.

The linearized Langmuir and Freundlich adsorption isotherms of TLR and GAC for COD are shown in Fig. 5 and Fig. 6 respectively. The Langmuir and 
Freundlich constants are displayed in Table 2. The higher regression values showed that the equilibrium data for COD fitted well to both the Langmuir and Freundlich isotherms in the studied concentration ranges. The essential characteristics of Langmuir isotherm can be expressed by a dimensionless constant (McKay et al., 1989) called equilibrium parameter, $\mathrm{E}_{\mathrm{p}}$, which is defined by
$\mathrm{E}_{\mathrm{p}}=1 /\left(1+\mathrm{bC}_{\mathrm{o}}\right)$

Where $b$ is the Langmuir constant and $\mathrm{C}_{0}$ is the initial COD concentration (mg/l), Ep values indicate the type of isotherm. Ep value between zero and one indicate favorable adsorption. The $\mathrm{E}_{\mathrm{p}}$ values were found to be 0.17 and 0.04 for TLR and GAC respectively for the concentration studied, suggesting favorable adsorption.
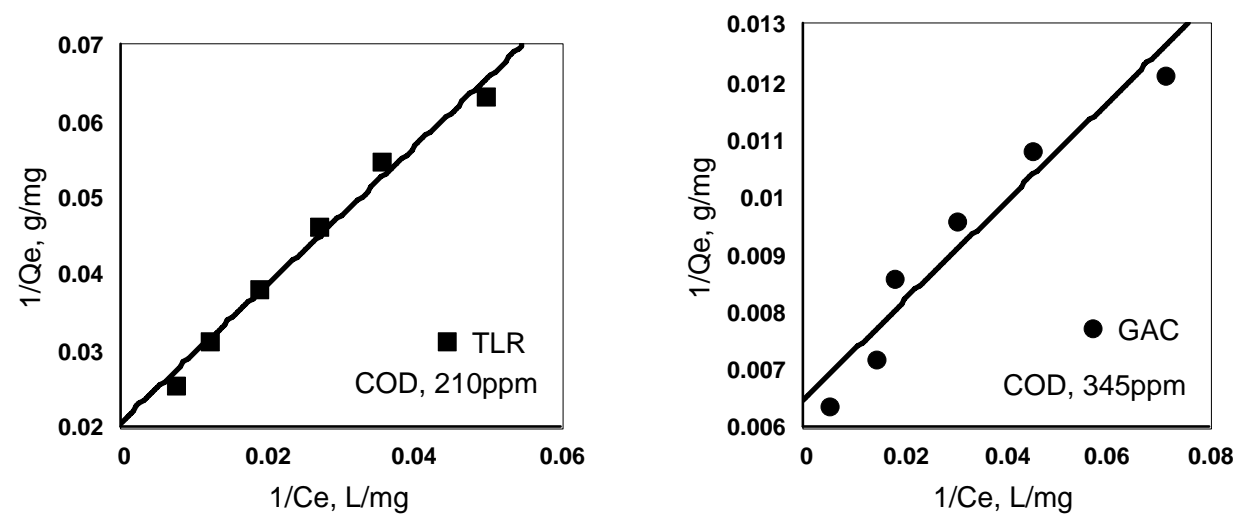

Fig 5. The linearized Langmuir Adsorption Isotherm for COD with TLR and GAC

Based on the correlation coefficients, the equilibrium data was slightly better fitted in the Freundlich adsorption isotherm than the Langmuir equation. The higher value of $\mathrm{K}_{\mathrm{F}}$, the Freundlich constant, showed easy uptake of COD from effluent solution. Also the higher value of $n$, which reflects the intensity of adsorption, signifies that the surface of the biosorbent is heterogeneous in nature and high enough for effective separation (Khalid et al., 2000). In a multicomponent mixture like molasses based effluent, competition phenomena give rise to different adsorption behavior.
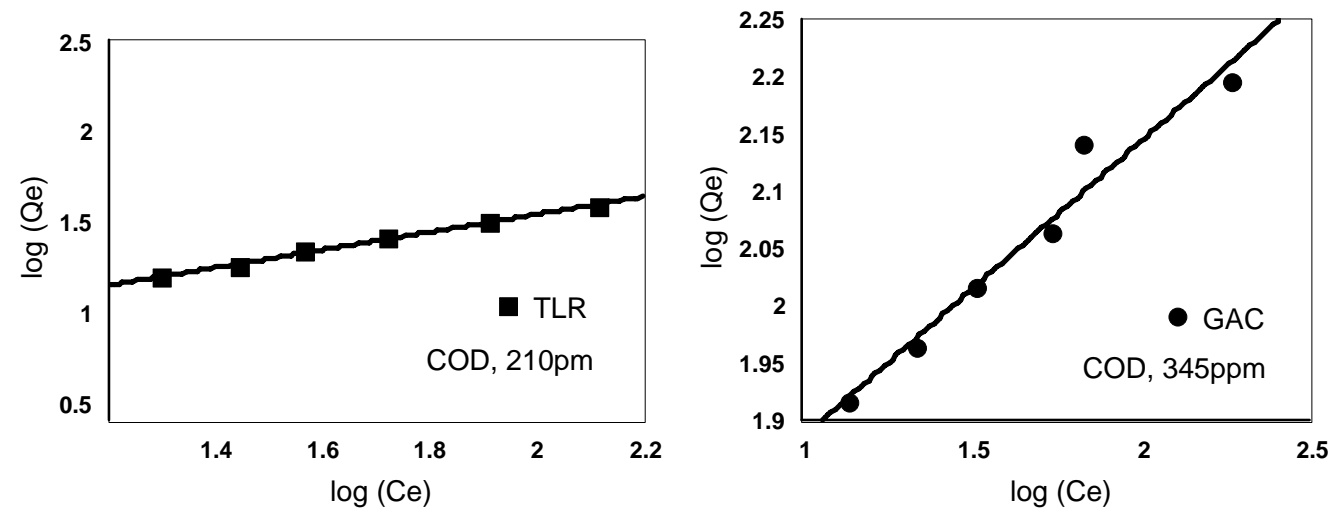

Fig 6. The linearized Freundlich Adsorption Isotherm for COD with TLR and GAC.

In this study, tendu leaves refuse from local bidi industry was evaluated to remove COD from organic matter rich effluent. The COD removal capacity of tendu leaves refuse was one third of that of granulated activated carbon. Tendu leaves refuse from local bidi industry is not used for any purpose and is disposed into roadside pits. Its accumulation around garbage dumping sites is creating a big menace. Considering dire need for its disposal, easy 
availability and zero cost makes tendu leaves refuse a potential biosorbent for industrial application.

Acknowledgement: Authors are grateful to Prof. R. K. Trivedy, Head, Department of Environmental Sciences, University of Pune, India, for providing laboratory facilities and encouragement.

\section{REFERENCES}

Abia, A A; Horsfall, M Jnr; Didi, O (2003). The Use of Chemically Modified and Unmodified Cassava Waste for the Removal of $\mathrm{Cd}, \mathrm{Cu}$ and $\mathrm{Zn}$ ions from Aqueous Solution. J. Bioresource Technol. 90:345 -348.

APHA (1989). Standard methods for the examination of water and waste water, $17^{\text {th }}$ edition, (APHA Inc.,) Americal Public Health Association, New York.

Baig, S; Liechti, P A (2001). Ozone treatment for biorefractory COD removal. Water Sci Technol. 43:197-204.

Casey, T J (1997). Unit Treatment Processes in Water and Wastewater Engineering, John Wiley and Sons Ltd, England, pp113-114.

Chapman,H D; Pratt, P F (1961). Methods of analysis for soils, plants and waters. Agricultural Sciences Publications, University of California, Berkeley.

Gangagni Rao, A; Venkata Naidu, G; Krishna Prasad, K; Chandrasekhar Rao, N; Venkata Mohan, S; Jetty, A; Sarma, P.N (2004). Anaerobic treatment of wastewater with high suspended solids from a bulk drug industry using fixed film reactor (AFFR). Bioresource Technology, 93:241-248.

Gupta, V K; Mittal, A; Gajbe, V (2005). Adsorption and desorption studies of a water soluble dye, Quinoline Yellow, using waste materials. Journal of Colloid and Interface Science 284: 89-98.

Hickey, R F; Goodwin, S (1989). Anaerobic processes. Journal of Water Pollution Control Federation 61:814-821.

Nagda, G K; Ghole, V S; Diwan, A M
Ho, Y S; McKay, G (1999). Pseudo-second order model for sorption processes. Process Biochemistry 34:451-465.

Kadam, D G (2004). Studies on vermicomposting of tendu leaf (Diospyros melanoxylon Roxb.) refuse with emphasis on microbiological and biochemical aspects. -Ph.D. thesis, Shivaji University, Kolhapur, India. Pp 14-20.

Khalid, N; Ahmad, S; Toheed, A; Ahmad, J (2000). Potential of rice husks for antimony removal. Applied Radiation and Isotopes, 52:30-38.

Krishnan, K A; Anirudhan, T S (2002). Removal of mercury(II) from aqueous solutions and chloralkali industry effluent by steam activated and sulphurised activated carbons prepared from bagasse pith: kinetics and equilibrium studies. Journal of Hazardous Materials B92:161-183.

Lewicki, W (2001). An introduction to vinasse (cms) from beat and cane molasses fermentation. International Sugar Journal 103:126-128.

Maiorella, B L; Blanch, H W; Wilkie, G R (1983). Distillery effluent treatment and by-product recovery. Process Biochemistry 18:5-8.

McKay, G; Blair, H; Gardiner, J R (1989). The adsorption of dyes onto chitin in fixed bed column and batch adsorbers. J Appl Polymer Sci. 28:1499-1514.

Namasivayam, C; Radhika, R; Suba, S (2001). Uptake of dyes by a promising locally available agricultural solid waste: coir pith. Waste Management 21:381-387.

Rajkumar, D; Palanivelu, K (2004). Electrochemical treatment of industrial wastewater. Journal Of Hazardous Materials 113:125-131.

Sarin, V; Pant, K K (2006). Removal of chromium from industrial waste by using eucalyptus bark. Bioresource Technology 97:15-20.

Sontheimer, H; Crittenden, J C; Summers, R.S (1988). Activated Carbon for Water Treatment, 2nd ed. DVGW-Forschungsstelle, Karlsruhe, Germany. 